\title{
Permissive hypotensive resuscitation in patients with traumatic hemorrhagic shock
}

Kai-Hung Ho ${ }^{1}$, Yih-Wen Tarng ${ }^{4}$, Yi-Pin Chou ${ }^{1,3,5^{*}}$ and Hsing-Lin Lin ${ }^{2^{*}}$

\begin{abstract}
We read the article "Risks and benefits of hypotensive resuscitation in patients with traumatic hemorrhagic shock: a meta-analysis" by Natthida Owattanapanich et al. with great interest and found it to be insightful. In our commentary, we propose possible reasons why mortality was lower in the permissive hypotension group and how the need for blood transfusion decreased in this group. No significant difference in acute kidney injury (AKI) was evident among patient groups, possibly because all these patients might have AKI. However, we do agree that permissive hypotension is of considerable benefit to trauma patients and worth further study.
\end{abstract}

To the Editor:

Sir,

We read the article "Risks and benefits of hypotensive resuscitation in patients with traumatic hemorrhagic shock: a meta-analysis" by Natthida Owattanapanich et al. [1] with great interest. The study provided the evidences of using hypotensive resuscitation for reducing mortality, the need for blood transfusions, the incidence of acute respiratory distress syndrome, and multiple organ dysfunction in traumatic hemorrhagic shock patients without inducing significant acute kidney injury (AKI). Permissive hypotension might be used for critical patients who require transfer to trauma center or pre-operation in extreme situations. Short-term hypotension is acceptably tolerated if the bleeding in the trauma patient is not severe, which signifies that the patient may only have small-artery bleeding rather than large-vessel injury. However, if patients condition continues to deteriorate, intravenous fluids should be immediately administered because such patients are at a high risk of mortality. Therefore, compared with patients not subject to aggressive resuscitation efforts, it is not surprising that the mortality rate is higher among these patients.

\footnotetext{
* Correspondence: chou2763e@yahoo.com.tw; hsinglin2002@yahoo.com.tw ${ }^{1}$ Division of Trauma Surgery, Department of Emergency, Kaohsiung Veterans General Hospital, 386, Da-Chung 1st Road, Kaohsiung 813, Taiwan

2Division of Acute Care Surgery, Department of Critical Care Medicine, Kaohsiung Veterans General Hospital, 386, Da-Chung 1st Road, Kaohsiung City 813, Taiwan

Full list of author information is available at the end of the article
}

In addition, the need for blood transfusion can be reduced in patients who receive appropriate procedures to stop bleeding-time is a critical factor in the process. If the bleeding can be stopped in a short time through timely appropriate treatment, the necessary volume of blood transfused can be reduced, obviating the need for permissive hypotension. Time is also critical in cases of AKI when the patient is in shock, but AKI can occur in any patient experiencing shock regardless of whether they receive aggressive resuscitation. Therefore, it is difficult to compare the outcome of AKI in patients all have AKI. Younger patients are known to recover faster from AKI; therefore, subgroup analysis could be performed on the basis of age.

In permissive hypotension, a trauma patient is treated with restricted fluid resuscitation, and permissive hypotension is a major topic in trauma research recently [2]. Another treatment employed during operation is deliberate hypotension, which is applied during orthopedic surgery [3]. These two treatments aim to control systolic blood pressure, maintaining it within $80-100 \mathrm{mmHg}$, and to decrease bleeding from the arteries of an injured person or an operative site. Permissive hypotension can be applied preoperatively and perioperatively; however, after bleeding is stopped through invasive interventions, it is necessary to maintain normal blood pressure and sufficient urine output. Permissive hypotension can be applied in trauma patients who respond to resuscitation; however, major trauma patients who do not respond to resuscitation, even aggressive fluid resuscitation, may

(c) The Author(s). 2019 Open Access This article is distributed under the terms of the Creative Commons Attribution 4.0 International License (http://creativecommons.org/licenses/by/4.0/), which permits unrestricted use, distribution, and 
have higher mortality, and permissive hypotension should not be applied in these patients.

Currently, no consensus strategy governs when or how to administer permissive hypotension during resuscitation. Further study should investigate the acceptable duration of low blood pressure and its tolerability.

\section{Acknowledgements}

Not applicable.

\section{Funding}

No funding was received for this commentary. The authors paid the article processing charges.

\section{Availability of data and materials}

Data sharing is not applicable to this article because no data sets were generated or analyzed during the current study.

\section{Authors' contributions}

HLL conceived the commentary. All three authors (KHH, YWT, and YPC) contributed equally to the writing of the manuscript. All authors read and approved the final manuscript.

\section{Ethics approval and consent to participate}

Not applicable.

\section{Consent for publication}

Not applicable.

\section{Competing interests}

The authors declare that they have no competing interests.

\section{Publisher's Note}

Springer Nature remains neutral with regard to jurisdictional claims in published maps and institutional affiliations.

\section{Author details}

'Division of Trauma Surgery, Department of Emergency, Kaohsiung Veterans General Hospital, 386, Da-Chung 1st Road, Kaohsiung 813, Taiwan. ${ }^{2}$ Division of Acute Care Surgery, Department of Critical Care Medicine, Kaohsiung Veterans General Hospital, 386, Da-Chung 1st Road, Kaohsiung City 813, Taiwan. ${ }^{3}$ Division of Thoracic Surgery, Department of Surgery, Kaohsiung Veterans General Hospital, 386, Da-Chung 1st Road, Kaohsiung, Taiwan.

${ }^{4}$ Department of Orthopaedic, Kaohsiung Veterans General Hospital, 386, Da-Chung 1st Road, Kaohsiung, Taiwan. ${ }^{5}$ Department of Cosmetic Science, College of Human Ecology, Chang Gung University of Science and

Technology, Kweishan, Taoyuan, Taiwan.

Received: 21 December 2018 Accepted: 30 January 2019

Published online: 12 February 2019

\section{References}

1. Owattanapanich N, Chittawatanarat K, Benyakorn T, Sirikun J. Risks and benefits of hypotensive resuscitation in patients with traumatic hemorrhagic shock: a meta-analysis. Scand I Trauma Resusc Emerg Med. 2018:26:107.

2. Chatrath V, Khetarpal R, Ahuja J. Fluid management in patients with trauma: restrictive versus liberal approach. J Anaesthesiol Clin Pharmacol. 2015;31: 308-16.

3. Jiang J, Yue Y, Bo L, Zhou R. Deliberate hypotension for orthopaedic surgery. Cochrane Database Syst Rev. 2016. https://www.cochranelibrary. com/cdsr/doi/10.1002/14651858.CD012096/epdf/full.

Ready to submit your research? Choose BMC and benefit from:
- fast, convenient online submission
- thorough peer review by experienced researchers in your field
- rapid publication on acceptance
- support for research data, including large and complex data types
- gold Open Access which fosters wider collaboration and increased citations
- maximum visibility for your research: over 100M website views per year
At BMC, research is always in progress.
Learn more biomedcentral.com/submissions

